\title{
INVENÇÃO E DESCOBERTA NA AULA DE MATEMÁTICA: UM PROJETO DE ENSINO, NO 6읏NO DO ENSINO FUNDAMENTAL
}

\section{INVENTION AND DISCOVERY IN MATH CLASSROOM: A TEACHING PROJECT IN ELEMENTARY SCHOOL'S 6TH GRADE}

\author{
Marcos Antonio Gonçalves Júnior \\ Centro de Ensino e Pesquisa Aplicada à Educação / Universidade Federal de Goiás / \\ margonjunior@gmail.com \\ Luciana Parente Rocha \\ Centro de Ensino e Pesquisa Aplicada à Educação / Universidade Federal de Goiás / \\ Ipr.luciana@gmail.com \\ Moema Gomes Moraes \\ Centro de Ensino e Pesquisa Aplicada à Educação / Universidade Federal de Goiás / \\ gmoraes002@gmail.com
}

\section{Resumo}

Esse artigo tem por objetivo relatar a experiência de um projeto de ensino, desenvolvido por um grupo de professores, em turmas de 60 anos do Ensino Fundamental, no Centro de Ensino e Pesquisa Aplicada à Educação (CEPAE) da Universidade Federal de Goiás (UFG), particularmente no tocante a metodologia de ensino desenvolvida, a saber, a Resolução de Problemas e a Investigação Matemática. Tais metodologias fundamentamse, principalmente, nos trabalhos de Polya $(1978 ; 2006)$, Ponte $(1998,2003)$, Butts (1997) e Buriasco (1995), as quais os professores basearam-se para fazer adaptações para a sala de aula. Especificamente, o presente trabalho discute e propõe modos de estruturar a dinâmica da aula de matemática e o desenvolvimento das atividades e seus enunciados, de acordo com a proposta metodológica. Por fim, apresenta duas narrativas de aula, tomando-as como referência para refletir sobre a experiência do projeto e para avaliar os desafios do papel do professor, sobretudo a mediação pedagógica dentro de ambientes de descoberta e invenção, como os propostos.

Palavras-chave: Educação Matemática. Resolução de Problemas. Investigação Matemática. Dinâmica da aula de matemática. Narrativas.

\section{Abstract}

This paper aims to report the experience of a teaching project developed by a group of 6th grade's teachers at the Center for Education and Research Applied to Education (CEPAE) of the Federal University of Goiás (UFG). Specifically, intends to discuss the teaching methodology developed, namely Problem Solving and Mathematical Investigations, based 
on Polya (1978; 2006), Ponte (1998, 2003), Butts (1997) and Buriasco (1995), which the teachers based themselves to make adaptations for the classroom. The teaching project discusses and proposes ways of structuring the dynamics of the mathematics class and the development of activities and their statements, according to the methodological proposal. Finally, it presents two narratives, taking them as reference to reflect on the experience of the project and to evaluate the challenges of the teacher, especially pedagogical mediation in contexts of discovery and invention, as proposed.

Keywords: Mathematics Education. Problem Solving. Mathematical Investigations. Class Design. Narrative.

\section{Introdução}

Esse artigo tem por objetivo relatar a experiência de um projeto de ensino, desenvolvido em turmas de 60 anos do Ensino Fundamental, no Centro de Ensino e Pesquisa Aplicada à Educação (CEPAE) da Universidade Federal de Goiás (UFG), particularmente no tocante a metodologia de ensino desenvolvida, a saber, a Resolução de Problemas e a Investigação Matemática.

A ideia desse projeto surgiu a partir de reflexões sobre a própria prática dos professores envolvidos, de discussões coletivas sobre a proposta pedagógica de educação matemática no CEPAE, assim como da experiência com os projetos de Estágio Supervisionado. Nessas reflexões, percebemos que os desafios do 'ser professor' são vários. Se, de um lado, há a preocupação com o cumprimento dos conteúdos do currículo, por outro, há uma inquietação por parte dos professores com: as dificuldades apresentadas pelos estudantes em matemática, a falta de autonomia em seu processo de estudo pedagógico, a cultura ainda muito comum entre eles de estudarem para fazer as provas, aproveitando pouco os momentos em aula, a concepção de que fazer matemática é para poucos (é para os matemáticos!), a pouca compreensão e a falta de argumentação em matemática, entre outras.

Há também as preocupações profissionais relacionadas à organização da escola e das aulas como um todo e como isso interfere ou influencia a sala de aula. As aulas intermitentes de uma mesma disciplina - aula simples, aula dupla, quando muito parecem sugerir uma certa incapacidade de nossos estudantes de se engajarem em uma mesma tarefa com persistência. Indicam, também, juntamente com a concepção de currículo como uma enorme lista de conteúdos a se cumprir, ainda mais em tempos de Base Nacional Curricular Comum (BNCC), que a aula, consequentemente a escola, não é o espaço adequado para pensar sobre as 'coisas', pensar com calma, com resiliência, com liberdade, com tempo para errar e recomeçar, para mudar o rumo, para rever, refazer, enfim.

A escola tem uma organização bastante limitadora nesse sentido e procurar meios de enfrentar essa questão a fim de propor mudanças não é uma tarefa simples, pois envolve uma série de sujeitos e processos complexos. Entretanto, como professores, incomodados com isso, resolvemos subverter, de forma responsável e criativa (D'AMBRÓSIO; LOPES, 2014), a ordem escolar pré-estabelecida e a nossa própria 
prática, começando por um lugar específico: a nossa sala de aula. E esse começo de um processo de mudança em sala de aula, envolvendo a Resolução de Problemas e a Investigação Matemática, comporta um desafio triplo para os professores: 1. Pensar em modos de estruturar a dinâmica das aulas de matemática e o desenvolvimento das atividades, dentro da proposta metodológica; 2. (Re)Pensar o currículo; 3. E, por fim, pensar na avaliação.

No presente artigo, daremos foco ao primeiro desafio, pois ele surgiu imediatamente quando nós, professores, nos colocamos a seguinte pergunta geral: Como melhorar nossas aulas de matemática? E, depois, de maneira mais restrita, a seguinte: Como inserir a Resolução de Problemas e a Investigação Matemática em nossas aulas, de modo a dar voz e autonomia aos estudantes, sem perder de vista os conteúdos de matemática do 60 ano?

Criamos, então, um grupo de estudos e pesquisa, intitulado "Abakós: Práticas Formativas e Colaborativas em Educação Matemática na Escola", no qual professores de matemática do CEPAE, professores formadores do Instituto de Matemática e Estatística (IME/UFG), estagiários do IME e outros, se reúnem quinzenalmente com o objetivo de discutir suas práticas de ensino, apresentando propostas, realizando-as em sala de aula e refletindo no grupo os resultados alcançados. Isso nos deu apoio e justificativas para propor mudanças em nossa prática, envolvendo-nos em um projeto de pesquisa ação colaborativa.

Antes do projeto, a carga horária das turmas dos sextos anos era de 4 horas semanais. Com o início do projeto, pleiteamos o aumento da carga horária para 5 horas semanais, distribuídas da seguinte forma: duas delas ministradas na sala de aula por um professor e as outras três aulas, sequenciais, ministradas simultaneamente por dois professores, no Laboratório de Educação Matemática (LEM) do CEPAE. Nestas aulas, propusemos atividades envolvendo Resolução de Problemas e a Investigação Matemática, nas quais o aluno ocupa um papel central. Naquelas, o professor desempenhava um papel central, sendo aulas mais expositivas e preocupadas com a realização de exercícios e sistematização dos conceitos trabalhos nas aulas do LEM.

Dado esse contexto, o que faremos aqui, neste artigo, é apresentar nosso ponto de vista, quando pensamos em aulas com essas estratégias metodológicas, apresentar a narrativa de duas aulas por nós ministradas no âmbito do projeto e fazer uma reflexão crítica.

\section{Invenção e descoberta em sala de aula de matemática}

Se alguém se depara com uma porta fechada da qual a chave está perdida e, automaticamente, usa um celular e aciona um chaveiro profissional para abri-la, a situação está longe de se configurar como um problema de fato, pois a sua resolução já estava dada de antemão e o resolvedor não precisou pensar em caminhos, estratégias, fazer tentativas, improvisar, errar, entre outros, a fim de resolver a situação.

Um problema, antes de mais nada, é uma espécie de empecilho que não sabemos ao certo como remover e, caso ele seja superado, o problema estará solucionado. A sua 
solução é previsível, ou seja, é possível imaginar a situação sem o obstáculo. Entretanto, a sua resolução não está dada. Os caminhos e as estratégias não estão explícitos, mas a solução imaginada tem o poder de sugerí-los, de indicá-los, de nos fazer intuí-los.

Um olhar mais conceitual sobre "problema" pode ser encontrado no dicionário de filosofia. Segundo Abbagnano (1982): a) quando nos deparamos com uma certa situação indeterminada que constitui um ponto de partida para indagação; b) diante dessa situação nos vemos na necessidade de refletir conscientemente para alcançar um determinado fim que possivelmente a melhorará; c) para isso há uma necessidade de procurar, de inventar, de investigar, de supor, de propor, de testar, enfim, de pensar. Então essa situação se constitui num problema.

A referida situação da porta fechada, se resolvida com uma ligação de celular, não se configuraria como um problema, pois os itens b e, sobretudo, o item c, definidos anteriormente, não aconteceriam de fato. Mas, se o resolvedor iniciasse um processo de tentativas, por exemplo, adaptar um pedaço de arame na fechadura, procurar meios de abrir essa porta, evolvendo-se em um processo consciente de pensamento focado na remoção desse obstáculo, então a situação em questão se configuraria como um problema. Como diz Dewey (1910, p. 12), o "problema fixa o fim [finalidade] do pensamento e o fim controla o processo de pensamento", pois trata-se de um processo de descoberta, visto que o resultado é, de antemão, imaginado. Do ponto de vista do aluno, isso nem sempre significa descortinar o já aprendido, o já existente, pois para ele a descoberta de algo pode ser uma atividade realmente criativa, como encontrar algo novo.

Claro que existem diferentes enunciados de problemas, se considerarmos nossos livros didáticos. Dessa forma, haverá nuances no significado dessa definição, quando pretende-se categorizá-los. Alguns problemas dão mais margem para pensar em diferentes estratégias e estão abertos a ter diferentes soluções. Outros problemas são mais fechados e dão pouca possibilidade à criatividade. Ainda, além das características do enunciado, há a experiência do resolvedor. Após anos lecionando matemática, por vezes, deixamos de nos surpreender com um problema e podemos até esquecer o quão instigante ele já nos foi um dia. Ainda, podemos também considerar aquilo que o professor é capaz de fazer a partir de um simples enunciado de um livro, transformando uma série de contas em uma aula desafiadora, por exemplo.

No entanto, vamos renunciar a todas essas nuances, por enquanto, e pensar simplesmente no enunciado de exercícios e problemas, tal como os conhecemos, nos livros didáticos. A classificação a seguir, dada por Butts (1997), é uma tentativa de fazer isso. Esse autor apresenta cinco tipos diferentes de enunciados:

Quadro 1 - Tipos de enunciados de exercícios e problemas

\begin{tabular}{|c|c|}
\hline $\begin{array}{c}\text { Tipo de } \\
\text { enunciado }\end{array}$ & Descrição \\
\hline $\begin{array}{c}\text { Exercícios de } \\
\text { reconhecime } \\
\text { nto }\end{array}$ & $\begin{array}{c}\text { São os que pedem ao resolvedor apenas para reconhecer ou recordar } \\
\text { um fato, uma definição ou o enunciado de uma teorema }\end{array}$ \\
\hline
\end{tabular}




\begin{tabular}{|c|c|c|}
\hline $\begin{array}{c}\text { Exercícios } \\
\text { algorítmicos }\end{array}$ & $\begin{array}{c}\text { O próprio nome já sugere que são aqueles exercícios nos quais há um } \\
\text { algoritmo ou um procedimento passo a passo para sua solução }\end{array}$ \\
\hline $\begin{array}{c}\text { Problemas de } \\
\text { aplicação }\end{array}$ & $\begin{array}{c}\text { São aqueles nos quais a principal tarefa a ser realizada é transformar a } \\
\text { linguagem do enunciado do problema em linguagem matemática }\end{array}$ \\
\hline $\begin{array}{c}\text { Problemas de } \\
\text { pesquisa } \\
\text { aberta }\end{array}$ & $\begin{array}{c}\text { São problemas cujo enunciado não sugere estratégias para sua } \\
\text { resolução. Normalmente, solicitam que o resolvedor prove algo, } \\
\text { encontre todos os casos possíveis, etc }\end{array}$ \\
\hline $\begin{array}{c}\text { Situações- } \\
\text { problema }\end{array}$ & $\begin{array}{c}\text { São situações em que o resolvedor deve primeiro identificar o(s) } \\
\text { problema(s) inerente(s). Não há um problema explícito, há uma } \\
\text { situação para se pensar. }\end{array}$ \\
\hline
\end{tabular}

Fonte: Butts (1997)

Buriasco (1995, p. 2) salienta que os três primeiros tipos são os que mais se encontram nos livros didáticos e que o "fato de conterem a estratégia para sua resolução nos próprios enunciados é característica comum entre eles". Desse modo, concordamos com Buriasco (1995) que a experiência de resolver um problema, de fato, tal como o definimos anteriormente, só pode ser vivenciada com os "problemas de pesquisa-aberta" e com as "situações-problema", pois, nesses tipos de enunciado, faz-se necessário refletir sobre o que fazer e quais as melhores formas para tal. Nos outros tipos está em jogo, principalmente, o paradigma do exercício, que também tem seu papel no pensamento matemático mas, tradicionalmente, tem sido o que os livros e professores costumam enfatizar.

Acrescentamos, ainda, com base em Ponte (2005), as características "aberto" e "fechado" aos enunciados dos problemas. Um exercício costuma ser uma tarefa fechada, pois leva sempre a um único resultado e dificilmente tem variadas maneiras de resolvê-lo. Um problema, nessa mesma lógica, também pode ser fechado. Será mais aberto quanto mais exploratória e investigativa for a tarefa sugerida por ele, quanto mais indeterminados forem os caminhos para a sua resolução e as possíveis respostas.

Essa taxonomia não pode, e não pretende, limitar nosso campo de ação. O próprio Butts (1997) nos alerta que cabe ao professor reelaborar e transformar o enunciado de um exercício ou problema a fim de deixá-lo mais aberto, ou mais exploratório, ou mais investigativo.

Os enunciados do tipo "situação-problema" e "problema de pesquisa aberta", por exemplo, guardam alguma semelhança com o que se tem chamado "investigação matemática, em sala de aula" (PONTE, 2003). Se, em um problema, o empecilho a ser vencido é claro, a investigação matemática, por sua vez, se caracteriza por lidar com uma situação para a qual os caminhos de resolução não estão explícitos, justamente por que a própria solução final é obscura. Acontece que o obstáculo que precisa ser retirado, tão nítido e característico de um problema, não se apresenta assim em um processo de investigação. A situação tem mais a aparência de um mistério a ser compreendido, de uma intriga a ser explicada, como no questionamento seguinte: "Percebi que somar dois números pares resulta em outro número par. Mas, como? Por quê isso acontece? Isso 
sempre acontece? Isso acontece somente com números pares? Como aconteceria com outros números?" A situação toma uma forma diferente dependendo de quais perguntas anteriores investiremos nossos esforços e, além disso, o processo de perguntar e perguntar parece não ter fim. Poderíamos acrescentar uma série de outras: "Nesse caso, o que acontece se subtrairmos números? E se multiplicarmos? Poderíamos sair do campo dos naturais para pensar nesse problema? Como?". Na investigação, o primeiro passo é compreender o problema com o qual vamos lidar e, a partir daí, inventar sua solução.

O artista Paul Valéry ${ }^{1}$ (1871-1945), ao ser indagado pelo Professor Hadamard sobre o processo de invenção, em uma pesquisa na qual se buscava entender o processo criativo de matemáticos e de outros profissionais, afirma o seguinte:

É preciso ser dois para inventar. Um forma as combinações, o outro escolhe, reconhece o que deseja e o que the importa no conjunto dos produtos do primeiro. O que se chama "gênio" não é tanto o ato daquele o que combina - e sim a prontidão deste para compreender o valor do que acaba de se produzir e para agarrar esse produto. (VALÉRY apud HADAMARD, 2009).

O processo de criação matemática é fértil em dúvidas e hesitações, como afirma Ponte (2003) e é essa a principal diferença entre uma investigação e um problema e também é uma grande oportunidade de aprendizado, como veremos.

$\mathrm{Na}$ resolução de problemas, como coloca Polya (2006), o processo envolve: 1. Compreender o problema; 2. Estabelecer um plano de ação; 3. Executar o plano e 4. Fazer um retrospecto (revisar e verificar). Por outro lado, conforme Ponte (2003), o processo da investigação matemática em sala de aula envolve: 1. Reconhecer a situação problemática; 2. Formular conjecturas; 3. Testar e refinar conjecturas e 4. Justificar e demonstrar.

O que temos procurado realizar em nosso projeto é colocar essas ideias em ação, em um contexto específico de uma sala de aula do 60 ano, resolvendo a dinâmica prática da aula, guardando ainda uma relação com o currículo. Ao invés de colocar as ideias da Resolução de Problemas e da Investigação Matemática de um lado e o paradigma do exercício, da rotina e da memorização de outro, procuramos ouvir a advertência de Freudenthal (1981): esse antagonismo é um dos grandes problemas da educação matemática, ele não nos leva a nada. Pensamos que essas ideias poderiam conviver dentro de uma mesma proposta.

O quadro 2 apresenta, então, as três concepções de aulas nas quais nos baseamos para realizar o projeto.

Nossa proposta metodológica para o ensino de matemática, com base no quadro 2, ocorreu em dois ambientes principais: o Laboratório de Educação Matemática (LEM) e a sala de aula.

\footnotetext{
1 Ambroise Paul Toussaint Jules Valéry foi um filósofo, escritor e poeta francês da escola simbolista cujos escritos incluem interesses em matemática, filosofia e música. Hadamard (2009), interessado no processo criativo e no processo de invenção, entrevistou uma série de matemáticos, em sua pesquisa. Assim, ele incluiu Valéry entre seus entrevistados.
} 
No LEM, as três aulas sequenciais adotavam a estratégia de, quase sempre, realizar um trabalho em trios, ou grupos de quatro alunos, lidando com um problema ou uma situação a ser investigada.

Nesse ambiente, tanto nas aulas de Resolução de Problemas, como nas de Investigação Matemática, buscávamos trabalhar com os nossos aprendizes o que Freudenthal (1981, p.143) chama de "atitude matemática" (mathematical attitude). Isso envolve, dentre outros aspectos, saber identificar a estrutura matemática dentro de um contexto, compreender o grau de precisão matemática adequado em um problema, desenvolver o uso da linguagem matemática e lidar com seu "fazer matemática" como um conteúdo a ser trabalhado. São aspectos conectados com a atividade do matemático, mesmo sendo em outra esfera de atuação.

Quadro 2 - Tipos de aula de matemática

\begin{tabular}{|c|c|c|c|}
\hline & No Modelo Frontal & $\begin{array}{c}\text { Com Resolução de } \\
\text { Problemas }\end{array}$ & Com Investigação Matemática \\
\hline & $\begin{array}{l}\text { - Explica a matéria; } \\
\text { - Mostra exemplos; } \\
\text { - Propõe exercícios; } \\
\text { - Resolve-os no quadro; } \\
\text { - Propões outros } \\
\text { exercícios; } \\
\text { - Resolve-os no quadro; } \\
\text { - Propõe problemas; } \\
\text { - Corrige-os; } \\
\text { - Começa outro assunto. }\end{array}$ & $\begin{array}{l}\text { - Apresenta um } \\
\text { problema; Intervém } \\
\text { quando necessário; } \\
\text { - Discute com o os } \\
\text { alunos as soluções } \\
\text { apresentadas, as } \\
\text { heurísticas e os } \\
\text { conteúdos; } \\
\text { - Faz uma síntese em } \\
\text { busca de sistematização; } \\
\text { - Apresenta outro } \\
\text { problema. }\end{array}$ & $\begin{array}{l}\text { - Desafia os alunos; } \\
\text { - Avalia o progresso dos alunos e } \\
\text { intervém; } \\
\text { - Raciocina matematicamente } \\
\text { junto com os alunos sobre fatos } \\
\text { novos; } \\
\text { - Discute as soluções e } \\
\text { conteúdos; } \\
\text { - Faz uma reflexão sobre o } \\
\text { processo; } \\
\text { - Apresenta outra situação } \\
\text { problema. }\end{array}$ \\
\hline & $\begin{array}{l}\text { - São expectadores } \\
\text { passivos; } \\
\text { - Obedecem ao que o } \\
\text { professor solicita. }\end{array}$ & $\begin{array}{l}\text { - Tentam compreender o } \\
\text { problema, } \\
\text { individualmente ou em } \\
\text { grupo; } \\
\text { - Estabelecem e } \\
\text { executam um plano para } \\
\text { resolvê-lo; } \\
\text { - Refletem sobre o } \\
\text { trabalho realizado, } \\
\text { verificando e revisando; } \\
\text { - Apresentam, } \\
\text { comunicam e } \\
\text { compartilham as } \\
\text { diferentes soluções. }\end{array}$ & $\begin{array}{l}\text { - Compreendem uma situação } \\
\text { problema } \\
\text { individualmente ou em grupo; } \\
\text { - Identificam problemas possíveis, } \\
\text { na situação, explorando-a e } \\
\text { levantando questões; } \\
\text { - Organizam dados e formulam } \\
\text { conjecturas; } \\
\text { - Realizam testes e refinam a } \\
\text { conjectura; } \\
\text { - Justificam uma conjectura; } \\
\text { - Apresentam, comunicam e } \\
\text { compartilham as diferentes } \\
\text { conjecturas; } \\
\text { - Avaliam o raciocínio ou o } \\
\text { resultado do raciocínio. }\end{array}$ \\
\hline
\end{tabular}

Fonte: Adaptação dos autores com base em Buriasco (1995), que apresenta e critica o modelo frontal; Polya (1978) e Onuchic (1999), que apresentam a Resolução de Problemas e Ponte (1998; 2003), que apresenta a Investigação Matemática em sala de aula. 
Aliado a isso, consideramos, em termos gerais, a matemática como uma ocupação ou trabalho humano comprometida em resolver problemas; dotada de uma linguagem simbólica e um sistema conceitual, organizado de forma lógica; socialmente constituída e que necessita ser compartilhada e validada por outros (GODINO; BATANERO, 1995).

Queremos dizer que a atividade desenvolvida com os nossos estudantes comportava um elemento essencial: a comunicação e o compartilhamento de ideias. $E$ isso era feito de várias maneiras, a mais corriqueira delas era a assembleia final para apresentação e discussão dos resultados encontrados, ocasião onde havia trocas, mas também debates, por vezes acalorados, argumentação, matemática ou não, entre outros aspectos. Esse espaço de debate também acontecia, algumas vezes, no meio da atividade, quer dizer, antes que os alunos tivessem já elaborado uma resolução mais consistente pois, compartilhar as ideias, mesmo iniciais, aumentava a compreensão da situação e sugeria outros caminhos possíveis.

Em todo caso, seja no meio ou no fim, eram momentos em que nós professores procurávamos, ao máximo, nos conter, quer dizer, evitar dizer aos alunos os caminhos que gostaríamos que eles tomassem, mas permitir que a discussão do grupo fosse validando resultados, estratégias. Nossa postura baseava-se no "believing game" (HARKNESS, 2009), ou seja, dávamos voz aos alunos, acreditando nas ideias apresentadas por eles, estimulando-os a persistirem nelas e a investigarem, mesmo que fossem ideias muitos diferentes daquelas que estávamos esperando para a atividade. $O$ próprio grupo de estudantes, ao compartilhar as ideias em assembleia, encarregava-se de fazer uma espécie de crítica e apuração, nem sempre harmônica, fazendo com que os professores atuassem mais como mediadores a garantir um debate respeitoso e produtivo.

Desse modo, organizávamos a aula no LEM em 3 momentos principais, que eram comunicados aos estudantes a fim de que também organizassem seus registros escritos com base neles.

Quadro 3 - Os momentos da aula

\begin{tabular}{|c|c|c|}
\hline $\begin{array}{c}\text { Momento } \\
\mathbf{S}\end{array}$ & Orientações aos estudantes & $\begin{array}{l}\text { Frase chave } \\
\text { do momento }\end{array}$ \\
\hline 10 & $\begin{array}{l}\text { - Extrair os dados importantes do enunciado (situação); } \\
\text { - (Re) Formular a pergunta, com suas próprias palavras; } \\
\text { - Panejar a resolução e as ações. }\end{array}$ & $\begin{array}{l}\text { "O que é pra } \\
\text { ser } \\
\text { investigado?" }\end{array}$ \\
\hline 20 & $\begin{array}{l}\text { - Olhar as pistas; } \\
\text { - Anotar; } \\
\text { - Organizar os dados; } \\
\text { - Fazer testes; } \\
\text { - Conjecturar; } \\
\text { - Testar conjecturas; } \\
\text { - Sistematizar as ideias (tabelas, listas, esquemas, etc); } \\
\text { - Resolver. }\end{array}$ & $\begin{array}{l}\text { "Vamos testar } \\
\text { nossa ideia!" }\end{array}$ \\
\hline
\end{tabular}




\begin{tabular}{|l|l|c|}
\hline \multirow{3}{*}{ 3o } & $\begin{array}{l}\text { - Registrar as conclusões; } \\
\text { - Justificar cada uma das conclusões (argumentando } \\
\text { matematicamente); } \\
\text { - Compartilhar as descobertas; } \\
\text { - Ouvir o colega; } \\
\text { - Debater/conversar sobre as descobertas. }\end{array}$ & $\begin{array}{c}\text { "Vamos ouvir } \\
\text { o grupo!" }\end{array}$ \\
\hline
\end{tabular}

Fonte: autores

Esses momentos, embora pensados com antecedência, foram paulatinamente sendo construídos por nós, no decorrer das aulas. Fomos experimentando-os e adaptando-os, encontrando estratégias para lidar com os alunos e fazê-los atender a eles. A ideia de ter uma frase chave para cada momento nasceu da necessidade deles registrarem as ideias principais em cada momento.

A organização do terceiro momento foi pensada com o propósito de fazer com que os alunos socializassem suas conjecturas e descobertas. Para isso, solicitávamos com antecedência que alguns grupos se preparassem para apresentação. Os estudantes faziam um círculo e os orientávamos a levantarem a mão para comentarem sobre as descobertas e serem ouvidos por todos. Essas estratégias foram construídas e amadurecidas ao longo de nossa experiência.

Digamos que esta estrutura de organização das aulas vem ao encontro do questionamento feito por English (2002), em relação às prioridades da pesquisa em educação matemática para o século XXI: "Que tipos de ambientes promovem uma participação democrática, isto é, encorajam nossos estudantes a desenvolver-se, a testar, a expandir e a refinar cada vez mais sua própria compreensão poderosa?" (ENGLISH, 2002, p. 10, tradução nossa)

Já no outro ambiente, a sala de aula, na qual ocorriam duas aulas por semana, nos baseávamos no modelo frontal de ensino. Esse nome, propositadamente dado por Buriasco (1995), tem a intenção de reforçar a afronta desse modelo em relação ao tempo de aprendizagem de cada um, pois, nesse tipo de aula, o "o quê", o "quando" e o "como" aprender é definido pelo currículo, pelo professor. Claro que, cientes disso, nessas duas aulas, embora adotemos aulas mais expositivas, nas quais predominam a realização de exercícios, também procurávamos dialogar o tempo todo com os estudantes, ouvindo suas perguntas, conversando sobre os conceitos, etc. Nessas duas aulas ocorriam o momento de sistematizar o que acontecia nas atividades do LEM, de apresentar definições, propriedades, entre outros.

Cientes dessa crítica sobre a afronta, nos posicionamos para além do antagonismo entre os tipos de aulas apresentados no quadro 2. Mesmo em sala de aula, procuramos evitar essa afronta, iniciando um diálogo sobre as atividades do LEM, perguntando aos alunos quais eram as situações trabalhadas e as ferramentas matemáticas das quais lançaram mão. Assim, o papel do professor era o de esquematizar os processos utilizados, definí-los, ressaltá-los, conceituá-los, sistematizá-los. Em seguida, havia a proposição de exercícios para serem realizados em sala e tarefas para casa. Algumas 
vezes, as aulas nesse ambiente foram usadas para iniciar um conteúdo novo, como se deu por exemplo com a introdução do conceito de fração.

Neste tipo de proposta, entendemos que a avaliação não pode utilizar somente a prova como instrumento. Seria um contrassenso! Afinal, a riqueza e a complexidade do trabalho dos alunos não pode ser expressa por meio de testes. Por isso, elaboramos fichas de avaliação observando o registro escrito, a argumentação matemática e a capacidade de comunicação dos alunos. De modo geral, usamos três instrumentos de avaliação, procurando compor uma avaliação formativa e reguladora (HADJI, 1994; TREVISAN, et al, 2014), a saber: a ficha de avaliação, a prova e a averiguação da tarefas de casa.

Nas seções seguintes, narraremos duas aulas ocorridas nos sextos anos, no ambiente do LEM, a fim de compartilhar como essa proposta se desenrolou. A primeira, ocorrida no início de 2016, apresenta um proposta de investigação matemática, realizada a partir de uma situação na qual duas crianças jogam 'par ou ímpar'. A segunda narrativa, referente a uma aula realizada em 2017, envolve uma situação problema cujo desafio é o de elaborar uma estratégia de contagem para estimar a quantidade de folhas de uma árvore.

Para construir as narrativas nos baseamos nos registros dos alunos, recolhidos por nós, nos diários de campo que cada um dos professores manteve, durante as aulas do projeto, além de fotos feitas durante as atividades e também recorremos à nossa memória, posto que os três autores do presente texto são professores do projeto em questão.

O quadro a seguir apresenta uma síntese das características das duas atividades trabalhadas.

Quadro 4 - Características das atividades propostas nos episódios narrados

\begin{tabular}{|c|c|c|}
\hline Atividade & Par ou ímpar? Ímpar ou par? & O senso numérico dos bichos \\
\hline Tipo de Aula & Investigação Matemática & Resolução de Problemas \\
\hline Objetivos & $\begin{array}{l}\text { - Construir o conceito paridade, ao observar } \\
\text { padrões e regularidades, na sequência dos } \\
\text { números pares e ímpares, dentro de uma } \\
\text { investigação matemática. } \\
\text { - Utilizar a matemática para compreender e } \\
\text { analisar uma situação corriqueira. } \\
\text { - Instigar as primeiras ideias algébricas, } \\
\text { dentro de um contexto aritmético. }\end{array}$ & $\begin{array}{l}\text { - Discutir estratégias de contagem. } \\
\text { - Inventar uma estratégia matemática para } \\
\text { contar a quantidade de folhas de uma } \\
\text { árvore. } \\
\text { - Trabalhar as operações com números } \\
\text { naturais dentro de uma situação problema. }\end{array}$ \\
\hline Conteúdos & $\begin{array}{l}\text { - Sequências numéricas. } \\
\text { - Números pares e ímpares. } \\
\text { - Divisibilidade por dois. }\end{array}$ & $\begin{array}{l}\text { - Números naturais e suas operações. } \\
\text { - A ideia da multiplicação como proporção. }\end{array}$ \\
\hline $\begin{array}{l}\text { Classificação } \\
\text { do enunciado }\end{array}$ & Problema de pesquisa aberta & Situação-problema \\
\hline
\end{tabular}

Fonte: Autores 


\section{“Par ou ímpar? Ímpar ou par?”}

A aula foi iniciada com a pergunta "Quem já brincou de par ou ímpar?!" Por ser uma brincadeira corriqueira das crianças, rapidamente, a turma de 60 ano ficou interessada no assunto, pois o enunciado da atividade parecia aventar a possibilidade de existir uma estratégia vencedora no "par ou ímpar", como mostra a figura 1.

Muitos levantaram as mãos mostrando conhecer a brincadeira. Outros se perguntaram o que tinha de matemática nela. A maioria já quis logo jogar com o colega, conforme veremos nessa narrativa.

Figura 1 - Enunciado da Atividade "Par ou ímpar? Ímpar ou par?"

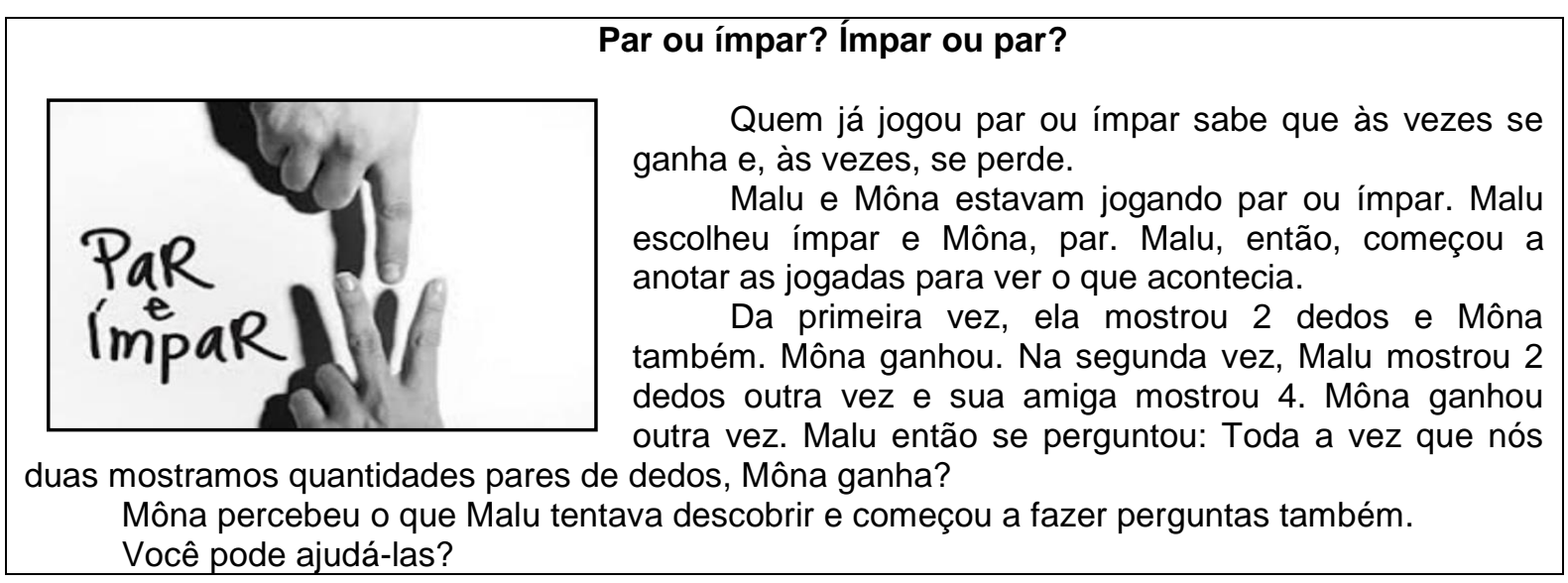

Fonte: Os autores.

Essa foi uma das primeiras atividades de investigação matemática do ano de 2016, era o início do nosso projeto e estudantes e professores estavam ainda aprendendo a lidar com atividades desse tipo. Assim, para auxiliá-los no registro, fixamos no LEM cartazes indicativos dos três momentos da aula, tal como consta no quadro $3 \mathrm{e}$, iniciando um hábito que se mantem até hoje, usamos as "frases chave" para conduzir a aula: 10) "O que é pra ser investigado?"; 2의 "Vamos testar nossa ideia!" e 3의 "Vamos ouvir o grupo!".

Os estudantes se sentaram em duplas e já começaram a brincar o "par ou ímpar", ávidos por jogar, nada preocupados com alguma sistematização ou registro das jogadas. Entregamos a eles latas com fichas numeradas de 0 a 9. Então, com nossa mediação, começaram a usar as fichas e a anotar, em uma folha, tanto o número retirado da lata, como a soma entre eles. Era o início do 2o- momento da aula.

Ao longo desse 20 momento, percebemos que, embora os estudantes estivessem fazendo contas e testes, eles não sabiam exatamente qual era o alvo da investigação. Eles jogavam e anotavam, tentavam responder se Môna ou Malu ganhariam a brincadeira, pareciam buscar uma resposta, sem mesmo saber a pergunta. Tudo indicava que jogavam por jogar, desprovidos de um senso investigativo. Foi quando retomamos as orientações em relação ao 10 momento, conversamos com a turma sobre as perguntas colocadas no enunciado: eram perguntas retóricas, usadas para 'puxar assunto'.

O 20 momento dessa atividade nos fez vislumbrar outro aspecto: a argumentação matemática. Para eles, apenas dois ou três testes eram suficientes para comprovar suas ideias, não vendo a necessidade de maior argumentação de suas hipóteses. Eles 
mesmos diziam ser óbvio que a soma de dois números pares resultava em outro par, mas não tinham uma boa justificativa para esse fato. Nossa orientação era para que seguissem investigando e procurassem justificar suas conjecturas.

Ao atendermos os grupos, nos deparamos com um estudante, L.B., que tinha uma conjectura a nos contar. L.B. era pouco participativo e chegou ao 60 ano com relatos de ser indisciplinado. Sua ideia era algo relativamente simples, diante dos objetivos da aula. Entretanto, com base no "believing game" (HARKNESS, 2009) nós não a rechaçamos, apenas procuramos instigá-lo a ir adiante, testá-la e, depois, buscar trabalhar avançando em outras conjecturas também interessantes.

Em seguida, demos início ao $3^{\circ}$ momento. L.B. e seu grupo foi um dos que apresentaram sua resolução à turma, como mostra o cartaz produzido pelo grupo, na figura 2.

Figura 2 - 3ำ Momento da Atividade "Par ou ímpar? Ímpar ou par?”. Registro do trio L.G.J.

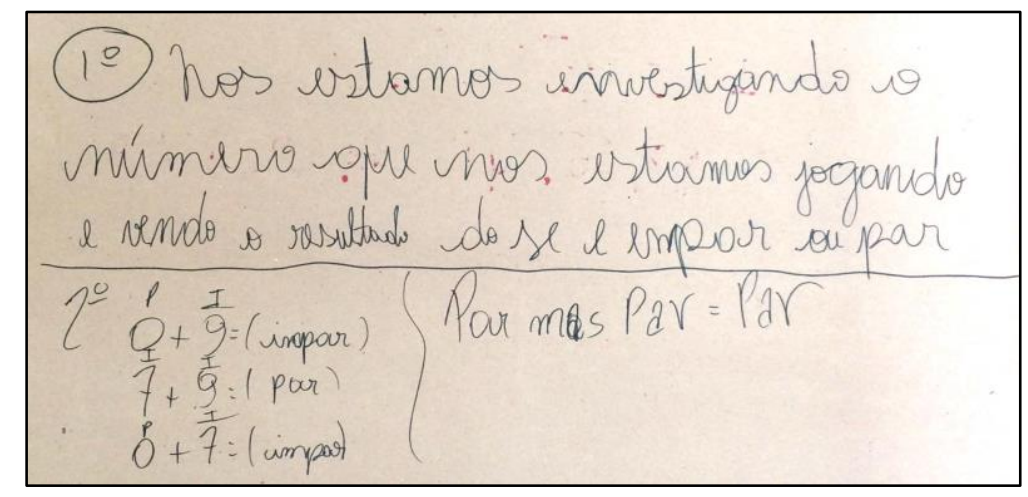

Fonte: Portfólio dos alunos, 2016, turma A.

Porém, L.B. não quis contar ao grupo a ideia que já havia nos contado. Insistimos e ele acabou falando, mas não registrou no cartaz. Encontramos sua conjectura no seu portfólio individual (figura 3).

Figura 3 - 3 omento da Atividade "Par ou ímpar? Ímpar ou par?". Registro do estudante L.B. ["Não importa a posição dos números não vai interferir no resultado"]

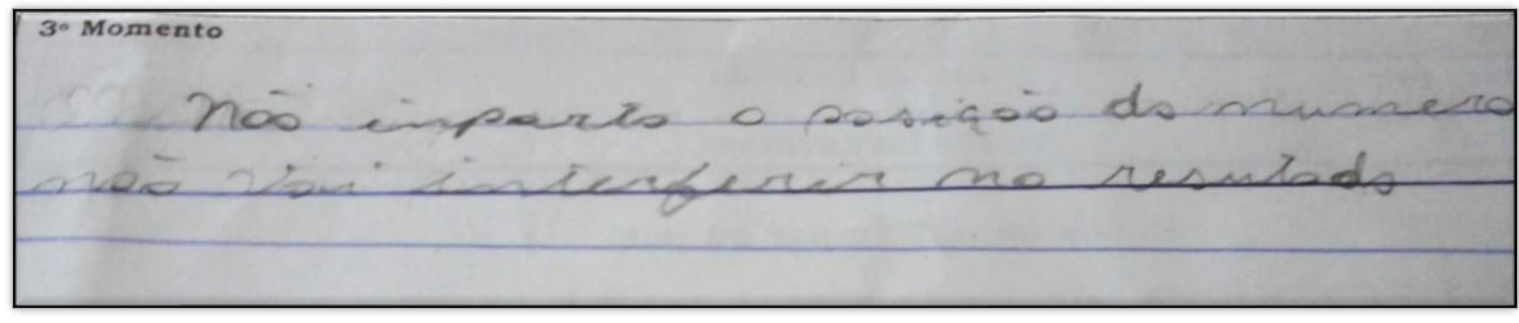

Fonte: Portfólio dos alunos, 2016, turma A. 
A turma fez algumas perguntas, procurando validar a ideia, mas ela não gerou grandes discussões. L.B. e seu grupo deram-se por satisfeitos e voltaram aos seus lugares. Passamos a palavra para outro grupo, o trio A.M.Y, cujo registro, apresentado em forma de cartaz, está na figura 4.

Figura 4 - 3o Momento da Atividade "Par ou ímpar? Ímpar ou par?”. Registro do trio

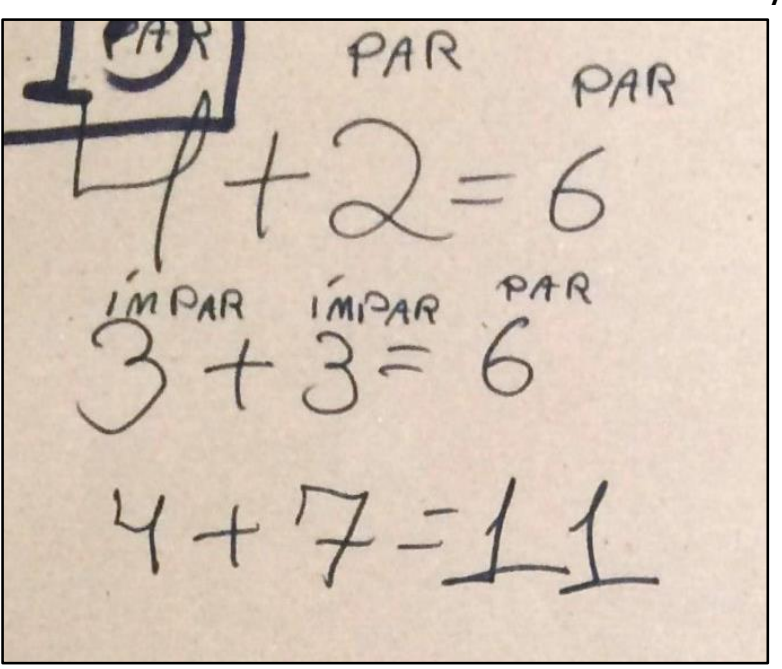
A.M.Y.

Fonte: Portfólio dos alunos, 2016, turma A.

Dois aspectos se sobressaem nesse registro. À esquerda, vemos que o grupo apresentou poucos testes para escrever conclusões, o que era reflexo do que havíamos também observado no portfólios individuais e, de certa forma, era algo natural para uma turma iniciante em investigação. No entanto - e agora o segundo aspecto -, eles tinham uma argumentação poderosa para justificar suas conjecturas, utilizando uma linguagem similar à algébrica, mas sem a sofisticação dos símbolos matemáticos. Com base nesse cartaz, o trio disse à turma, com suas palavras, algo como o seguinte:

- Um número par é como "um grupo de casais" e um ímpar é como "um grupo de casais mais um solteiro".

- Juntando dois "grupos de casais", obtemos um grande grupo de casais.

- Juntando dois grupos do tipo "grupo de casais mais um solteiro", os dois solteiros formarão um novo casal também.

- E juntando um "grupo de casais" com um "grupo de casais mais um solteiro", o solteiro permanecerá sozinho.

O fato de ainda não terem estudado álgebra, não os impediu de argumentar e demonstrar 'matematicamente' as conjecturas que haviam criado.

O coletivo, depois de discutir, mediado pelos professores, aprovou essa possibilidade de argumentação e, de certa forma, houve uma validação coletiva das ideias apresentadas. Nós, professores, concluímos a aula afirmando que eles haviam produzido muita matemática naquele dia. A turma aplaudiu. 
Semanas depois, L.B. passou a mostrar-se engajado em praticamente todas as atividades do LEM. Outro estudante, F.M., nos disse que sentia-se como um Einstein, durante essas aulas, por estar inventando matemática.

\section{"Os bichos sabem contar?"}

Com essa pergunta, demos o "arranque" a essa aula procurando instigar os estudantes a refletir sobre processos de contagem. Os professores trouxeram indagações como as contidas na figura 5 , a seguir:

Figura 5 - Trecho 1 do enunciado da atividade "O senso numérico dos bichos".

Alguém já tentou separar um ou dois filhotinhos, recém nascidos, de uma
cadela, sem que ela veja? Ao voltar, a mamãe cachorro fica exasperada, procurando
por seus filhotes.
Além dos cães, os elefantes, os macacos e outros bichos tem o que
chamamos de senso numérico. O Pintassilgo, por exemplo, um lindo passarinho
amarelo, já foi alvo de experimentos científicos, com os quais se descobriu que,
diante de um monte com 3 e outro com 4 sementes apetitosas, ou entre 6 e 3 , ele
consegue escolher o maior monte.

Fonte: Os autores.

E a história contida na figura 6 , a seguir, foi narrada pelos professores de maneira a dramatizar a anedota.

Após narrarmos a lenda do corvo e do escudeiro e sobre passarinhos, conforme constava no enunciado da atividade, contamos também algumas curiosidades sobre aranhas, macacos e outros animais que, como os corvos, também possuem um senso numérico. Abordamos, inclusive, estratégias de contagem mais sofisticadas, como a estimativa da quantidade de participantes em um grande evento.

Para nós, era importante estabelecer uma relação entre o senso numérico e as situações vividas pelos bichos, a fim de enfatizar que o homem vai além do senso numérico, pois usa e cria ferramentas que o auxiliam a contar. Desse modo, a situação problema proposta aos alunos foi: "O desafio de hoje é contar a quantidade de folhas de uma árvore".

Sabíamos da necessidade de desafiar os alunos para se engajarem na tarefa e nossa condução, passando pelas narrativas e estratégias de contagem, levou os alunos a observar pela janela, com mais atenção, as árvores do pátio do CEPAE. Previamente, havíamos escolhido duas árvores, como objeto de investigação. Entretanto, de onde estávamos, elas não podiam ser avistadas pela janela. Antes de mostrá-las, solicitamos aos estudantes para registrarem o 1ㅇ momento e estabelecer um plano de resolução, imaginando e esquematizando uma árvore, seus galhos e suas folhas e, assim, pensando e registrando procedimentos adequados para realizar tal estimativa. 
Figura 6 - Trecho 2 do enunciado da atividade "O senso numérico dos bichos".

\section{O corvo e o escudeiro}

A mando de seu amo, um escudeiro estava determinado a expulsar um corvo que havia feito um ninho em umas das torres do castelo, pois aquilo irritava sobremaneira 0 amo.

O escudeiro, então, tentou entrar na torre da forma mais silenciosa possível, a fim de capturar o corvo e destruir seu ninho. Mas, quando o corvo pressentia a presença de um homem, rapidamente se afastava até uma árvore próxima e esperava pacientemente o momento certo para retornar à torre, em segurança.

Após várias tentativas em vão, o escudeiro teve uma ideia:

"Dois homens entram e sobem na torre,

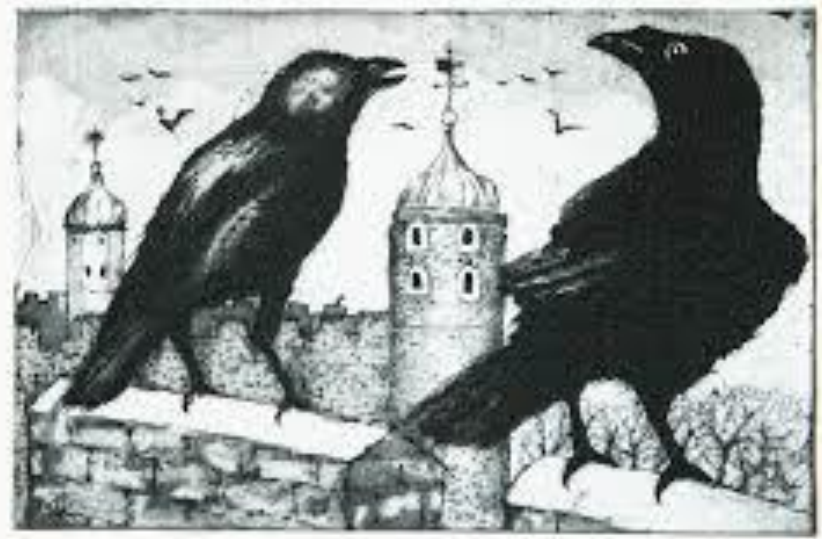
ao mesmo tempo, mas somente um deles desce e vai embora. O outro fica escondido na torre, perto do ninho do corvo. Assim, enganado, ao retornar para a torre, o corvo se tornará uma presa fácil."

Pobre escudeiro... De longe, o corvo observou a movimentação e não retornou para a torre, até que os dois homens estivessem do lado de fora.

O escudeiro, persistente e determinado, repetiu a ideia, dia após dia, mas aumentando a quantidade de homens. Subiram 3 homens e desceram dois... mas nada do corvo. Subiram 4 homens... nem sinal. Por fim, 5 homens galgaram a torre e quatro desceram. O pobre corvo perdeu-se na conta e retornou ligeiro para o seu ninho, sendo fatalmente capturado pelo escudeiro do castelo.

Fonte: História disponível no Livro: "From one to zero", de Georges Ifrah e no livro "Os números: a história de uma grande invenção", do mesmo autor, adaptada pelos autores para compor a atividade.

Em grupos de quatro pessoas, discutindo estratégias, embora alguns não chegaram a formalizar um plano de resolução, observamos dois tipos principais de planejamento: $O$ primeiro ilustra os que fizeram uma descrição passo a passo dos procedimentos a serem utilizados pelo grupo, como mostra a figura 7 .

Outro tipo de planejamento adotado por alguns grupos foi um modelo de árvore no qual pudessem estimar a quantidade de folhas, como as figuras 8 e 9 . Vale ressaltar que alguns educandos imaginaram apenas uma grande copa de árvore, estimando um total de folhas com base em seu senso numérico, como eles mesmos afirmaram (figura 8). Outros já imaginaram a complexidade dos galhos (grandes, pequenos) e utilizaram a ideia da multiplicação como proporção, estabelecendo uma relação folhas por galho (figura 9).

Após esse planejamento, iniciamos o $2^{\circ}$ momento, a turma saiu para 0 pátio e iniciou a observação das duas árvores indicadas pelos professores. Devido a uma brincadeira entre os professores e os estudantes, as árvores foram nomeadas de 'Mamute 1' e 'Mamute 2'. Porém, ao lado da 'Mamute 2', havia uma árvore menor, da mesma espécie, apelidada pelos alunos como 'Mamute Júnior' e que foi bastante utilizada como referência de contagem proporcional, ou seja, procuraram estabelecer uma relação entre a quantidade de folhas dessas duas árvores: 'Mamute Jr' e 'Mamute 2'. 
Figura 7 - 1을 Momento da Atividade "O senso numérico dos bichos". Registro do estudante

A.V.

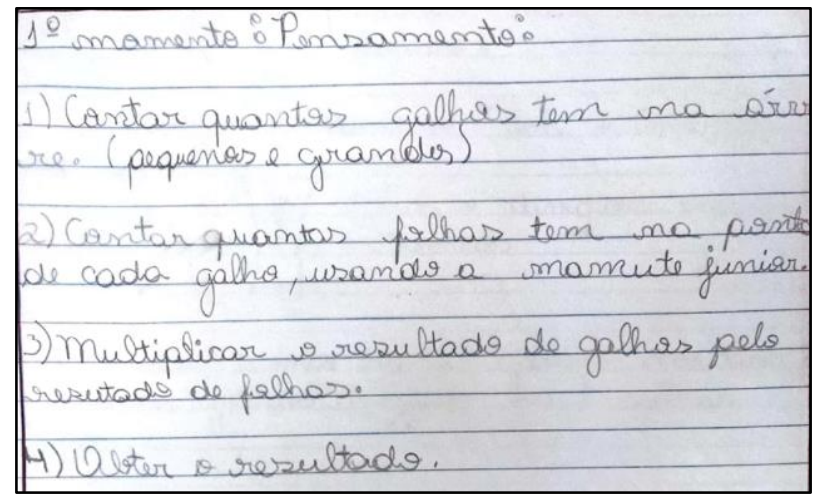

Fonte: Portfólio dos estudantes, 2017, turma A.
Figure 8 - 1을 Momento da Atividade "O senso numérico dos bichos". Registro do estudante E.R.

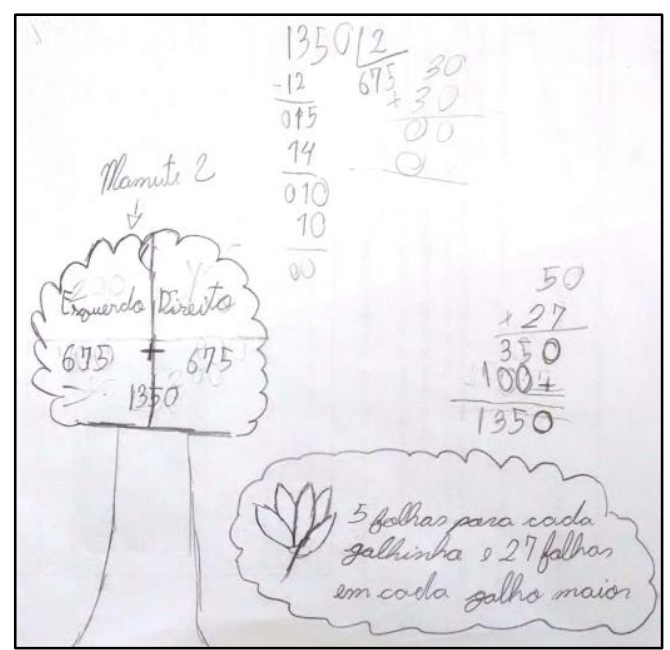

Fonte: Portfólio dos estudantes, 2017, turma B.

Nessa etapa, o plano dos estudantes encontrou algo inesperado, pois eles logo perceberam que o grande desafio era estimar a quantidade de cada tipo de galho da árvore (pequenos, grandes, médios) e estabelecer uma relação média: quantidade de folhas por tipo de galho. Assim, o registro feito por eles mostra uma reestruturação do plano, com base nessa percepção deles, como o exemplo da figura 9 e 10.

Figura 9 - 1으, 2ㅇ e 3으 momentos da Atividade "Senso numérico dos bichos". Registro do estudante G.A.F.R.G

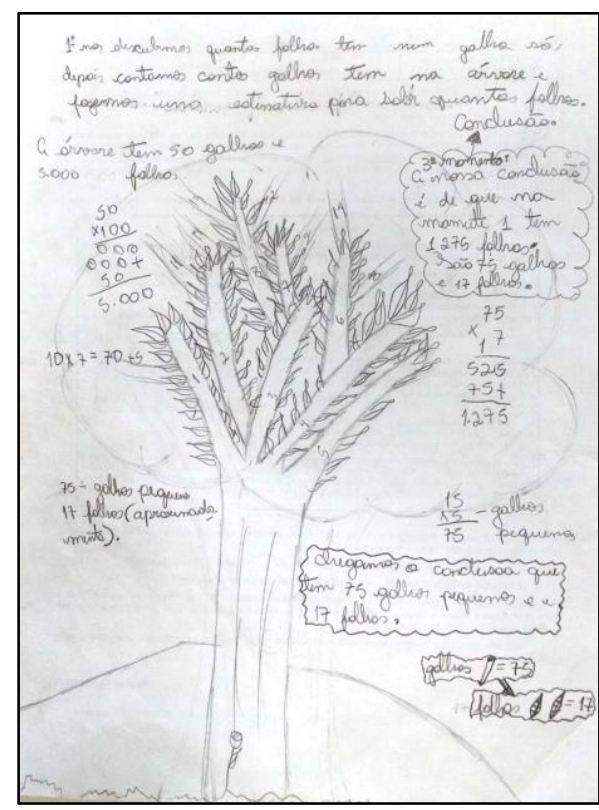

Fonte: Portfólio dos estudantes, 2017, turma B.
Figura 10 - 2ㅇ e 3o momentos da Atividade "Senso numérico dos bichos". Registro do estudante A.V.

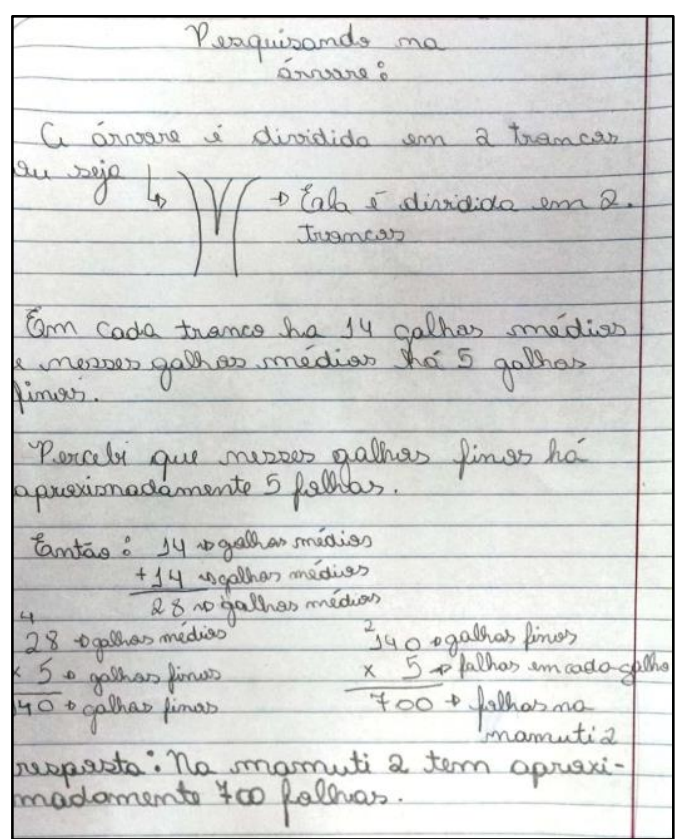

Fonte: Portfólio dos estudantes, 2017, turma A. 
Observando com mais atenção as figuras 7 e 10, pertencentes a um mesmo estudante, nota-se uma coerência entre o plano pré-estabelecido e a sua execução. Entretanto, isso não se deu com todos, pois a maioria sentiu a necessidade de reestruturar o plano e reformular as estratégias de resolução, ao se deparar com a árvore real. Essa necessidade se configurou tão desafiante para alguns estudantes a ponto de levá-los a preencher até seis folhas de anotações, na consecução do 2o momento. Há também aqueles que foram mais sucintos com resoluções breves e pouco detalhadas.

O 3 o momento, nesse dia, foi feito com a apresentação dos grupos, que sintetizaram suas resoluções em cartazes, fixados pelas paredes do LEM. Com isso, alguns grupos expuseram oralmente à turma suas estratégias e descobertas.

O debate na turma mostrou que alguns grupos contaram manualmente a quantidade de folhas da pequena árvore, apelidada de 'Mamute $\mathrm{Jr}$ ', e estimaram que a 'Mamute 2' teria aproximadamente 14 galhos semelhantes à 'Mamute Jr'. E assim chegaram a um resultado, que nos pareceu bem próximo à realidade, utilizando a ideia da multiplicação como proporção.

Já para a outra árvore, 'Mamute 1', notamos que apesar dos grupos utilizarem estratégias semelhantes (estabelecimento de uma relação 'folhas por galhos'), os resultados encontrados pelos grupos foram bastante diversos.

Questionamos a turma sobre esse fato e isso nos levou a conversar sobre outro conceito matemático, pois a justificativa apresentada por eles sobre tal divergência referiu-se ao fato de alguns grupos terem considerado os tamanhos dos galhos e terem estabelecido diferentes quantidades de folhas por galho. Um trio, E.S.A., disse que contou 18 folhas em um galho, 18 folhas em outro e $20 \mathrm{em}$ outro. Assim, considerou que a árvore continha em média 18 folhas por galho. Isso causou certo alvoroço na turma e o todos queriam falar ao mesmo tempo, muitos discordando veementemente da estratégia adotada, já que talvez o 18 poderia não ser o mais representativo, para o caso.

O calor da discussão no LEM e o pouco tempo que nos restava não permitiu ao grupo fechar o debate ou aprofundar o conceito, com a mediação dos professores. No entanto, a situação estava posta para que, na próxima aula, já no ambiente da sala de aula, o professor pudesse aproveitar esse ensejo, retomar a discussão e apresentar o conceito da divisão relacionado com o de média aritmética, além de outras ideias da multiplicação.

Como se vê, o senso numérico dos estudantes instigou sobremaneira o senso didático dos professores.

\section{Considerações finais}

As narrativas apresentadas procuraram dar ênfase à consecução dos três momentos por nós estabelecidos, conforme os objetivos do presente texto, tal como baseia-se o referencial teórico adotado. Assim, no que se refere às considerações finais, gostaríamos de destacar ainda alguns aspectos referentes a isso, mas também fazer um 
breve análise de nossos desafios como professores em processo de reflexão e pesquisa sobre nossa própria prática.

O 1ㅇ momento caracteriza-se por ser ponto de partida de aula no qual os professores precisam, de certo modo, cativar os alunos para o contexto do enunciado, instigando-os a pensar sobre algo. Notamos como esse início é importante, pois se não houver engajamento dos aprendizes, a atividade pode resultar pouco produtiva. Claro que temos ciência de que alguns estudantes simplesmente não se envolvem, como em qualquer atividade pedagógica. Mas também reconhecemos que a falta de dedicação pode ser consequência da incompreensão da situação ou da investigação a ser feita, como podemos ver na primeira narrativa apresentada, na qual os educandos iniciaram o jogo e, minutos depois, o interesse havia se perdido e o sentido da investigação não havia sido captado por eles. Se a atividade é uma investigação matemática, normalmente o desafio está em compreender e escrever o que deve ser investigado, pois a cultura da investigação não está inserida no contexto escolar. Após ler um enunciado, eles automaticamente iniciam as contas, resoluções sem pensar com atenção no objeto de investigação. Se a atividade envolve um problema, um dos desafios é estabelecer um plano de resolução, fazer o exercício de imaginar o "fim", o problema solucionado e, ainda, ter a flexibilidade de alterar o plano, a depender das intempéries do processo, como contamos na segunda narrativa. Como professores, temos aprendido que é preciso ensinar a eles o que é uma aula de investigação matemática, o que é conjectura, o que é um problema, etc.

À medida que a aula acontecia, o desafio para nós professores era identificar os 'sinais' emitidos pela turma e conduzir o tempo de forma a equilibrar os três momentos da aula, fazer a mediação entre os estudantes, o conhecimento e o seu processo de criação, evitando 'entregar' as respostas a eles.

A descentralização do papel do professor, nas aulas de LEM, sobretudo no $2^{\circ}$ momento, é sem dúvida o principal desafio para nós. Temos passado nossa vida de estudantes e, depois, como profissionais, a esperar que o professor investigue, conjecture, conclua, argumente, passe para o próximo passo, defina, proponha o próximo exercício, problema, enfim.

Quando o "believing game" (HARKNESS, 2009) começou a fazer parte de nossas aulas, passamos a conhecer nossos alunos de outro modo, passamos a respeitar o tempo deles e a encorajá-los a tomar os caminhos que eles estavam maduros a seguir, com suas próprias pernas e não a tomar o caminho único indicado pelo professor. Por vezes, o estudante excelente no "modelo frontal" sentia-se inseguro nas aulas do LEM e, por vezes, o aluno agitado, indisciplinado, sentia-se livre para colocar suas opiniões, argumentos e, por fim, ser ouvido, valorizado, tal como nos ensinou L.B., na primeira narrativa. Em aulas mais democráticas e participativas, como no LEM, eles se mostram de maneira diferente, quando comparados com a sala de aula, onde estão sentados nas carteiras, sempre em fila. $E$ isso interfere até mesmo nas relações afetivas entre professores e alunos mas, sobretudo, no processo avaliativo, já que nosso conhecimento da turma e do potencial de cada um é transformado, é munido de informações relevantes 
sobre o processo de aprendizagem que, até então, não enxergávamos, nas aulas no "modelo frontal".

Por fim, o 3o momento da aula, é a etapa na qual os educandos além de compartilhar a solução encontrada pelo grupo, discutem sobre as ideias que foram elaboradas na execução da atividade. É também um momento de reelaboração das ideias, pois ocorre a contraposição delas, surgem perguntas, entre os próprios alunos, que os fazem repensar seus caminhos investigativos. Um grande desafio dessa etapa é manter o respeito à fala do outro, seja no que se refere a escutar, seja no que se refere a criticar com cuidado. E um dos aspectos mais motivadores para os alunos é ver que sua fala, seu cartaz, sua resolução foi compreendida pela turma e validada.

As aulas no LEM nos indicam que alguns alunos têm mais facilidade em sustentar seu ponto de vista oralmente, que por meio do registro escrito. A narrativa 1 nos sinaliza que a linguagem metafórica utilizada pelos alunos para demonstrar a paridade dos números naturais é uma conquista no processo de aprendizagem e pode ser um caminho para se alcançar a linguagem matemática. Daí a importância de pensarmos em atividades investigativas para o desenvolvimento da autonomia dos educandos. Por isto, destacamos a atenção ao papel dos momentos de socialização das ideias, uma vez que, é neste espaço onde ocorrem as discussões sobre as descobertas dos grupos. Neles os jovens mais contestadores estimulam os colegas a pensar e argumentar as soluções desenvolvidas em grupo. Muitas ideias e conceitos são apreendidos ou mesmo reelaborados por meio deste diálogo mediado pelos professores. Trata-se, portanto, de uma perspectiva metodológica que, por meio da invenção e da descoberta em sala de aula, busca romper uma perspectiva conteudista de ensino da Matemática.

Frente às ordens institucionais e curriculares impostas a nós, tem sido um desafio enorme que, em nosso caso, vem sendo enfrentado por um processo colaborativo de investigação sobre a própria pratica e de mudança insubordinada, criativa e responsável, em nós mesmos como professores de matemática, como educadores.

\section{Referências}

BURIASCO, Regina L. C. de. Sobre a Resolução de Problemas (II). Nosso Fazer, Londrina, v.1, n. 6, p. 2-5,1995.

BUTTS, Thomas. Formulando problemas adequadamente. Em: KRULIK, Stephen; REYS, Robert. E. (Org.). A resolução de problemas na matemática escolar. São Paulo: Atual, p. 32-48,1997.

D'AMBROSIO, Beatriz; LOPES, Celi Espasandin. Trajetórias profissionais de educadoras matemáticas. Campinas, SP: Mercado de Letras, 2014.

DEWEY, John. How we think. Boston. MA: DC Heath, 1910.

ENGLISH, L. et al. Future Issues and Directions in International Mathematics Education Research. Em: ENGLISH, L (ed.) Handbook of international research in mathematics education. Mahwah, New Jersey, USA: Lawrence Erlbaum Associates, Inc., Publishers, 2002. 
FREUDENTHAL, H. Major problems of mathematics education. Educational Studies in Mathematics, v.12, n.2, 133-150. 1981.

GODINO, Juan. D.; BATANERO, Carmen.; NAVARRO-PELAYO, V. Epistemology and mathematics instruccion: implications for curricular development. Em: $V$ International Conference on Systematic Cooperation Between Theory and Practice in Mathematics Education, 1994, Grado, Italy. Anais... Pavia: ISDAF, p.9-18, 1994. Disponível em: <http://www.ugr.es/ jgodino/Teoria_Metodos/gradoesp.htm>. Acesso em: 6 jul. 2002.

HADAMARD, Jacques. Psicologia da invenção na matemática. Contraponto, 2009.

HADJI, Charles. A avaliação, regras do jogo. 4.ed. Portugal: Porto, 1994.

HARKNESS, Shelly Sheats. Social constructivism and the Believing Game: a mathematics teacher's practice and its implications. Educational Studies in Mathematics, v. 70, n. 3, p. 243-258, 2009.

ONUCHIC, Lourdes de la Rosa. Ensino-aprendizagem de Matemática através da resolução de problemas. In: BICUDO, M. A. V. (Org.) Pesquisa em educação matemática: concepções e perspectivas. São Paulo: UNESP, p. 199-218, 1999.

POLYA, George. A arte de resolver problemas. Rio de Janeiro: Interciência, v. 2, 1978.

PONTE, João Pedro da. O trabalho do professor numa aula de investigação matemática. Quadrante, v.7, n.2, p. 41-70, 1998.

Investigação sobre investigações matemáticas em Portugal. Investigar em educação, p. 93-169, 2003.

Gestão curricular em Matemática. In: GRUPO DE TRABALHO INVESIGTIVO (Ed.) O professor e o desenvolvimento curricular. Lisboa: APM, p.11-34, 2005.

PONTE, João Pedro. da.; BROCARDO, Joana; OLIVEIRA, Hélia. Investigações Matemáticas na sala de aula. Belo Horizonte: Autêntica, 2003.

TREVISAN, André Luis; MENDES, Marcele T.; BURIASCO, Regina L. C. de. O Conceito de Regulação no Contexto da Avaliação Escolar. Alexandria - Revista de Educação em Ciência e Tecnologia, v.7, n.1, p.235-250, 2014.

Submissão: 25/08/2017

Aceite: $30 / 11 / 2017$ 